\title{
Simultaneous Single Dexamethasone Implant and Ranibizumab Injection in a Case with Active Serpiginous Choroiditis and Choroidal Neovascular Membrane
}

\author{
Ali Osman Saatci Ziya Ayhan Ceren EnginDurmaz Omer Takes \\ Department of Ophthalmology, Dokuz Eylul University, Izmir, Turkey
}

\section{Key Words}

Choroidal neovascular membrane - Dexamethasone implant · Ozurdex - Ranibizumab ·

Serpiginous choroiditis

\begin{abstract}
Intravitreal anti-vascular endothelial growth factor (VEGF) agents seem to be effective in choroidal neovascular membranes (CNV) in association with various entities of posterior uveitis. We herein report a 46-year-old woman who was treated with a simultaneous single intravitreal dexamethasone implant and ranibizumab administration for the treatment of unilateral extrafoveal CNV associated with an active serpiginous choroiditis. Simultaneously with the intravitreal therapy, oral mycophenolic acid $(2 \times 720 \mathrm{mg})$ was started, and oral cyclosporine $(3 \times 100 \mathrm{mg}$ ) was then added 2 months later. On the other hand, the fellow eye had been treated for subfoveal CNV but with an inactive disease 4 years previously and ended up with a final visual acuity of counting fingers despite treatment with a single session of photodynamic therapy and 3 subsequent intravitreal ranibizumab injections. Simultaneous administration of anti-VEGF agents and a dexamethasone implant can be a viable approach in eyes with CNV and active serpiginous choroiditis.

(C) 2015 The Author(s)

Published by S. Karger AG, Basel
\end{abstract}

\begin{tabular}{ll}
\hline KARGER 125/s & $\begin{array}{l}\text { A. Osman Saatci } \\
\text { Mustafa Kemal Sahil Bulv. No. } 73 \\
\text { A Blok Daire } 9 \\
\text { TR-35320 Narldere Izmir (Turkey) } \\
\text { E-Mail osman.saatci@yahoo.com }\end{array}$
\end{tabular}


Saatci et al.: Simultaneous Single Dexamethasone Implant and Ranibizumab Injection in a Case with Active Serpiginous Choroiditis and Choroidal Neovascular Membrane

\section{Introduction}

Choroidal neovascular membranes (CNV) can be associated with various inflammatory chorioretinal diseases, as the cytokines together with the vascular endothelial growth factor (VEGF) are implicated in the pathogenetic mechanisms leading to an impaired permeability and altered angiogenesis [1, 2]. It is assumed that CNV may occur in up to $25 \%$ of cases with serpiginous choroiditis and may be detected at the time of active choroiditis or in between the inflammatory episodes [3]. In a systemic immunosuppressive therapy for eye disease cohort study, 81 eyes (2\%) had CNV at presentation among the 4,041 eyes of the 2,307 patients with posterior uveitis or panuveitis [4]. Of the 148 eyes with a diagnosis of serpiginous choroiditis, CNV was noted in 7 eyes (4.7\%). The presence of CNV must be differentiated from the signs of active disease as the treatment options may differ. We hereby report a case of active serpiginous choroiditis with CNV and discuss our therapeutic approach.

\section{Case Report}

A 42-year-old otherwise healthy woman with a visual loss of 2 months' duration in OD in 2009 was examined by us. Her best-corrected visual acuity was counting fingers (CF) at 1 $m$ in OD and 20/20 in OS. No sign of anterior chamber and vitreous inflammation was present. On fundus evaluation, there were chorioretinal scars surrounding the optic disc in a serpentine-like fashion $\mathrm{OU}$, together with a subfoveal grayish lesion and subretinal hemorrhage in OD (fig. 1). Our diagnosis was inactive bilateral serpiginous choroiditis and subfoveal classic CNV in OD. A single session of photodynamic therapy and 3 subsequent intravitreal ranibizumab injections were administered in a time span of 9 months without any visual improvement. Four years later, at the age of 46 , she was once again examined by us; this time for metamorphopsia and mild visual loss of 2 weeks' duration in OS. Visual acuity was $\mathrm{CF}$ at $1 \mathrm{~m}$ in OD and 20/30 in OS. While slit-lamp examination was normal in OD, there were ++ cells in the left vitreous. On fundus evaluation, there was a large macular scar and extensive chorioretinal scarring surrounding the optic disc in OD (fig. 2a, b). In OS, peripapillary scarring with active-looking creamy borders and a grayish lesion with a hemorrhagic rim in the papillomacular bundle were noted (fig. 2c). With the help of fluorescein angiography and optical coherence tomography (fig. $2 \mathrm{~d}-\mathrm{f}$ ), we reached a diagnosis of extrafoveal classic-type $\mathrm{CNV}$ in association with active serpiginous choroiditis in OS. In order to avoid systemic steroids, a single intravitreal dexamethasone implant was injected simultaneously with ranibizumab. The risks and benefits of the simultaneous intravitreal injection of the 2 drugs were explained to the patient, and an informed consent was obtained. At the same time, oral mycophenolic acid $2 \times 720 \mathrm{mg}$ was commenced. A week later, visual acuity was improved to $20 / 25$, and optical coherence tomography showed that intraretinal and subfoveal fluid had almost totally disappeared. During the follow-up of 22 months, no further injection was required, and no injection-related complication occurred. Oral cyclosporine $3 \times 100 \mathrm{mg}$ was added to the systemic therapy due to the persistent activity of the inflammation 2 months later. At the last visit, she was still on the same systemic regimen. Visual acuities were CF in OD and 20/25 in OS, and the left fundus was relatively stabilized (fig. 3). 
Saatci et al.: Simultaneous Single Dexamethasone Implant and Ranibizumab Injection in a Case with Active Serpiginous Choroiditis and Choroidal Neovascular Membrane

\section{Discussion}

A thorough control of underlying inflammation with the help of systemic steroids and/or immunosuppressives should be considered in eyes with active serpiginous choroiditis associated with CNV. However, local targeted therapy is often administered to treat the coexistent $\mathrm{CNV}$ to obtain a better anatomical and visual outcome.

In earlier days, argon laser photocoagulation was the preferred method for the treatment of extrafoveal CNV [5-7] and photodynamic treatment mostly for the juxtafoveal and subfoveal CNV in serpiginous choroiditis [8-10]. More recently, intravitreal anti-VEGFs were evaluated in eyes with serpiginous choroiditis and CNV [11-15]. Patients were followed up for 36 months to assess the efficacy of intravitreal bevacizumab administration in a retrospective multicenter consecutive case series comprised of 81 patients with inflammatory ocular neovascularization refractory to standard therapy [12]. Ten of those eyes had serpiginous choroiditis and $50 \%$ of the CNV was subfoveal. Half of these patients have already been on systemic steroids and/or immunosuppressives. The mean number of bevacizumab injections in those eyes was 2.5. On the other hand, eyes with multifocal choroiditis and CNV required a mean of 6.3 injections, eyes with ocular histoplasmosis a mean of 3.9 , and eyes with punctate inner choroidopathy a mean of 3.4 injections. Parodi et al. [15] reported their results of intravitreal bevacizumab administration in 7 eyes of 7 patients with CNV and serpiginous choroiditis who were followed up for a year with monthly follow-ups. All patients had also been on various systemic therapies. One eye required 5 bevacizumab injections, and the remaining eyes received only a single injection. Only 1 eye experienced a visual loss of 2 lines or more. The remaining 6 eyes either experienced visual gain, or the vision remained stable. Song and Roh [11] described a 44-year-old woman with inactive serpiginous choroiditis and juxtafoveal CNV. Two ranibizumab injections 2 months apart were sufficient to obtain a stable lesion without any concurrent systemic therapy. The patient was followed up for 6 more months after the second injection, and the visual acuity improved to 20/20 from the initial level of 20/40. In a group of 16 eyes of 15 consecutive patients with an inflammatory type of $\mathrm{CNV}$, eyes were treated with repeated intravitreal ranibizumab injections [13]. Only 2 of those patients had an inactive type of serpiginous choroiditis. Both patients received 2 ranibizumab injections. In 1 eye, visual acuity remained stable, and the other eye experienced a 15-letter improvement. The follow-up was 52 and 64 weeks, respectively. Balaskas et al. [14] reported a 55-year-old man with an already established diagnosis of inactive serpiginous choroiditis with an extrafoveal classic-type CNV. Following a 3-daily intravenous infusion of prednisolone $1 \mathrm{~g}, 2$ sessions of argon laser photocoagulation and then 2 photodynamic therapy treatments were performed. Upon worsening, 8 consecutive ranibizumab injections were given. The final visual acuity was 20/20.

In the present case with active serpiginous choroiditis and extrafoveal CNV, we preferred to intravitreally inject both ranibizumab and the dexamethasone implant simultaneously. The rationale for the dexamethasone implant was to suppress the active inflammation until the effect of the newly started immunosuppressive agent was commenced. There were some previous reports on the intravitreal steroid administration for the control of active inflammation in serpiginous choroiditis [16-18]. Wadhwa et al. [17] injected intravitreal triamcinolone acetonide in 8 eyes of 8 patients with active unilateral serpiginous choroiditis. They reported that remission was induced rapidly, and the visual acuities were either stabilized or improved after the follow-up of 6 months. Seth and Gaudio [18] placed a fluocinolone implant after the observation of a good disease control with a single intravitreal triamcinolone acetonide administration, and the visual outcome was satisfactory during a follow-up of 14 months. 
Saatci et al.: Simultaneous Single Dexamethasone Implant and Ranibizumab Injection in a Case with Active Serpiginous Choroiditis and Choroidal Neovascular Membrane

As there are no randomized studies for the treatment of CNV in association with inflammatory diseases, such as the ones associated with age-related macular degeneration and pathologic myopia, a tailored therapeutic approach seems to be more appropriate. It is well accepted that systemic or intravitreal steroids with or without systemic immunosuppressives should be employed in order to suppress the active inflammation. Anti-VEGF agents should also be administered in order to achieve a better anatomical outcome and visual acuity.

\section{Statement of Ethics}

Informed consent for medical therapy and publication was obtained from the patient.

\section{Disclosure Statement}

The authors declare that there are no conflicts of interest regarding the publication of this article.

\section{References}

1 Parodi MB, Iacono P, Verbraak FD, Bandello F: Antivascular endothelial growth factors for inflammatory chorioretinal disorders. Dev Ophthalmol 2010;46:84-95.

-2 D'Ambrosio E, Tortorella P, Iannetti L: Management of uveitis-related choroidal neovascularization: from the pathogenesis to the therapy. J Ophthalmol 2014;2014:450428.

3 Agarwal A: Serpiginous choroiditis (geographic choroiditis, helicoid peripapillary choroidopathy); in Agarwal A, Singh A: Gass's Atlas of Macular Diseases, ed 5. Philadelphia, Elsevier Saunders, 2012, pp 962969.

4 Baxter SL, Pistilli M, Pujari SS, Liesegang TL, Suhler EB, Thorne JE, et al: Risk of choroidal neovascularization among the uveitides. Am J Ophthalmol 2013;156:468-477.

5 Jampol L, Orth D, Daily MJ, Rabb MF: Subretinal neovascularization with geographic (serpiginous) choroiditis. Am J Ophthalmol 1979;88:683-689.

-6 Laatikainen L, Erkkila H: Subretinal and disc neovascularization in serpiginous choroiditis. Br J Ophthalmol 1982;66:326-331.

7 Lee DK, Augustin W, Buggage RR, Suhler EB: Serpiginous choroidopathy presenting as choroidal neovascularization. Br J Ophthalmol 2003;87:1184-1194.

-8 Navajas EV, Costa RA, Farah ME, Cardillo JA, Bonomo PP: Indocyanine green-mediated photothrombosis combined with intravitreal triamcinolone for the treatment of choroidal neovascularization in serpiginous choroiditis. Eye 2003;17:563-566.

-9 Park SP, Ko DA, Chung H, Yu HG: Photodynamic therapy with verteporfin for juxtafoveal choroidal neovascularization in serpiginous choroiditis. Ophthalmic Surg Lasers Imaging 2006;37:425-428.

$\$ 10$ Lim JI, Rao NA: Photodynamic therapy with verteporfin for serpiginous choroiditis with subfoveal choroidal neovascularization. Retin Cases Brief Rep 2007;1:3-4.

-11 Song MH, Roh YJ: Intravitreal ranibizumab for choroidal neovascularisation in serpiginous choroiditis. Eye 2009;23:1873-1875.

12 Mansour AM, Arevalo JF, Fardeau C, Hrisomalos EN, Chan WM, Lai TY, et al: Three-year visual and anatomic results of administrating intravitreal bevacizumab in inflammatory ocular neovascularization. Can J Ophthalmol 2012;47:269-274.

13 Rouvas A, Petrou P, Douvali M, et al: Intravitreal ranibizumab for the treatment of inflammatory choroidal neovascularization. Retina 2011;31:871-879.

14 Balaskas K, Ur Rehman S, D’Souza Y: Long-term ranibizumab treatment for choroidal neovascularization secondary to serpiginous choroiditis. Can J Ophthalmol 2012;47:e15-e17.

15 Parodi MB, Iacono P, La Spina C, Knutsson KA, Mansour A, Arevalo JF, Bandello F: Intravitreal bevacizumab for choroidal neovascularisation in serpiginous choroiditis. Br J Ophthalmol 2014;98:519-522.

16 Karacorlu S, Ozdemir H, Karacorlu M: Intravitreal triamcinolone acetonide in serpiginous choroiditis. Jpn J Ophthalmol 2006;50:290-291. 
Case Reports in

Ophthalmology

\begin{tabular}{l|l}
\hline Case Rep Ophthalmol 2015;6:408-414 \\
\hline DOI: 10.1159/000442346 & $\begin{array}{l}\text { (c) 2015 The Author(s). Published by S. Karger AG, Basel } \\
\text { www.karger.com/cop }\end{array}$ \\
\hline
\end{tabular}

Saatci et al.: Simultaneous Single Dexamethasone Implant and Ranibizumab Injection in a Case with Active Serpiginous Choroiditis and Choroidal Neovascular Membrane

17 Wadhwa N, Garg SP, Mehrotra A: Prospective evaluation of intravitreal triamcinolone acetonide in serpiginous choroiditis. Ophthalmologica 2010;224:183-187.

18 Seth RK, Gaudio PA: Treatment of serpiginous choroiditis with intravitreous fluocinolone acetonide implant. Ocul Immunol Inflamm 2008;16:103-105.
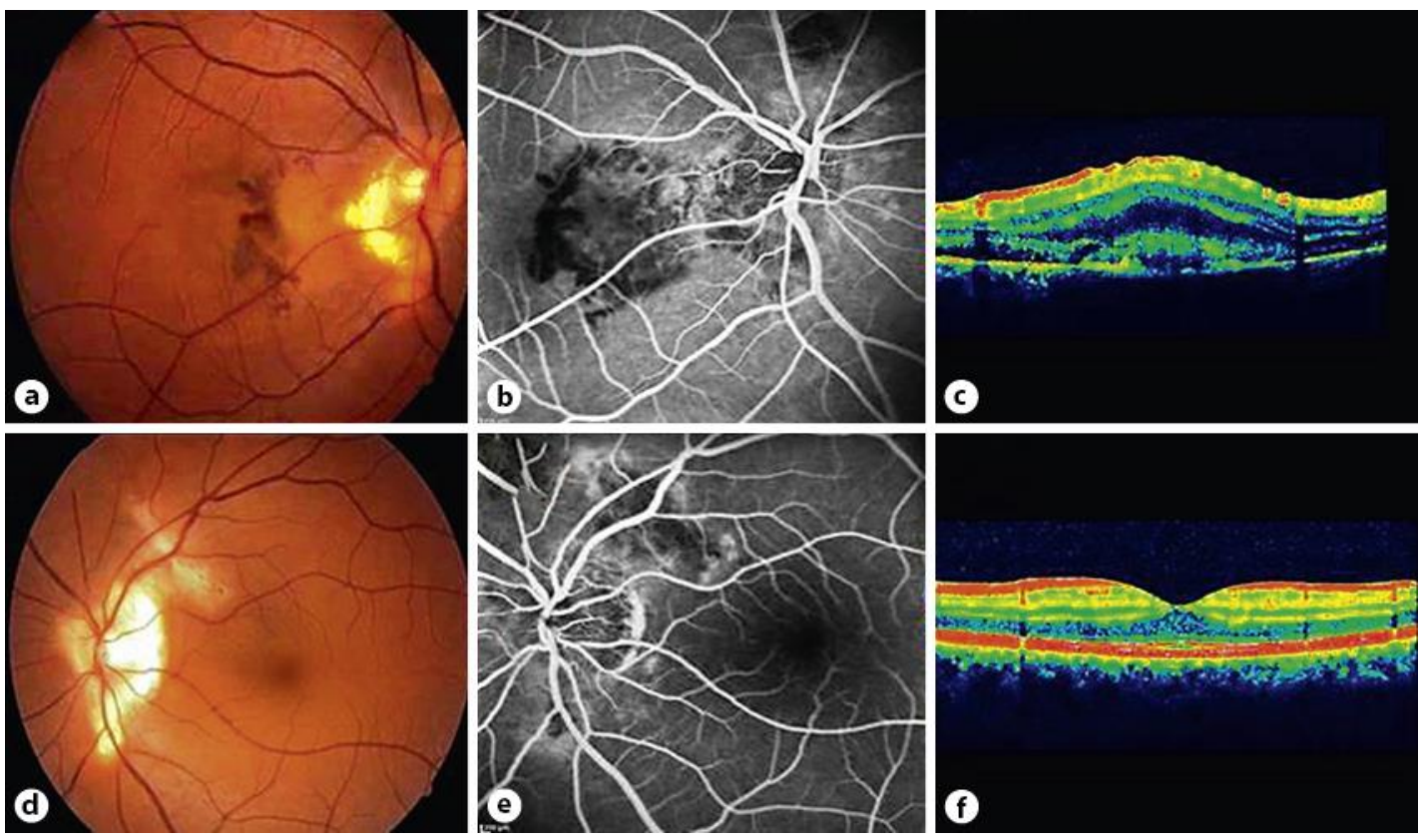

Fig. 1. Right eye. a Color fundus picture: peripapillary scarred area with foveal grayish lesion with subretinal hemorrhage. $\mathbf{b}$ Venous phase of fluorescein angiogram: lacy subfoveal hyperfluorescence associated with a hypofluorescent rim. c OCT scan: foveal hyperreflective material, intraretinal and subretinal fluid. Left eye. $\mathbf{d}$ Color fundus picture: peripapillary chorioretinal scarring. e Venous phase of fluorescein angiogram: normal macula. $\mathrm{f}$ OCT scan: normal foveal contour. 


\section{Case Reports in Ophthalmology}

\begin{tabular}{l|l}
\hline Case Rep Ophthalmol 2015;6:408-414 \\
\hline DOI: 10.1159/000442346 & $\begin{array}{l}\text { ○ 2015 The Author(s). Published by S. Karger AG, Basel } \\
\text { www.karger.com/cop }\end{array}$ \\
\hline
\end{tabular}

Saatci et al.: Simultaneous Single Dexamethasone Implant and Ranibizumab Injection in a Case with Active Serpiginous Choroiditis and Choroidal Neovascular Membrane
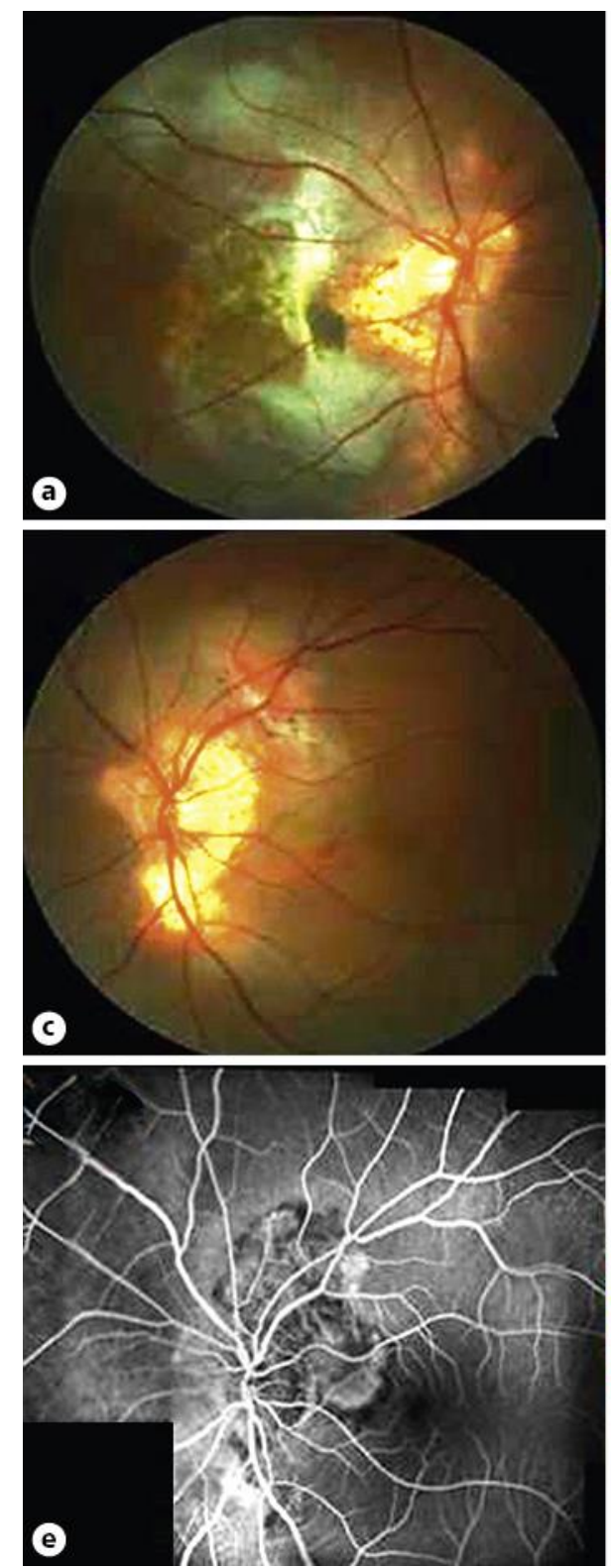
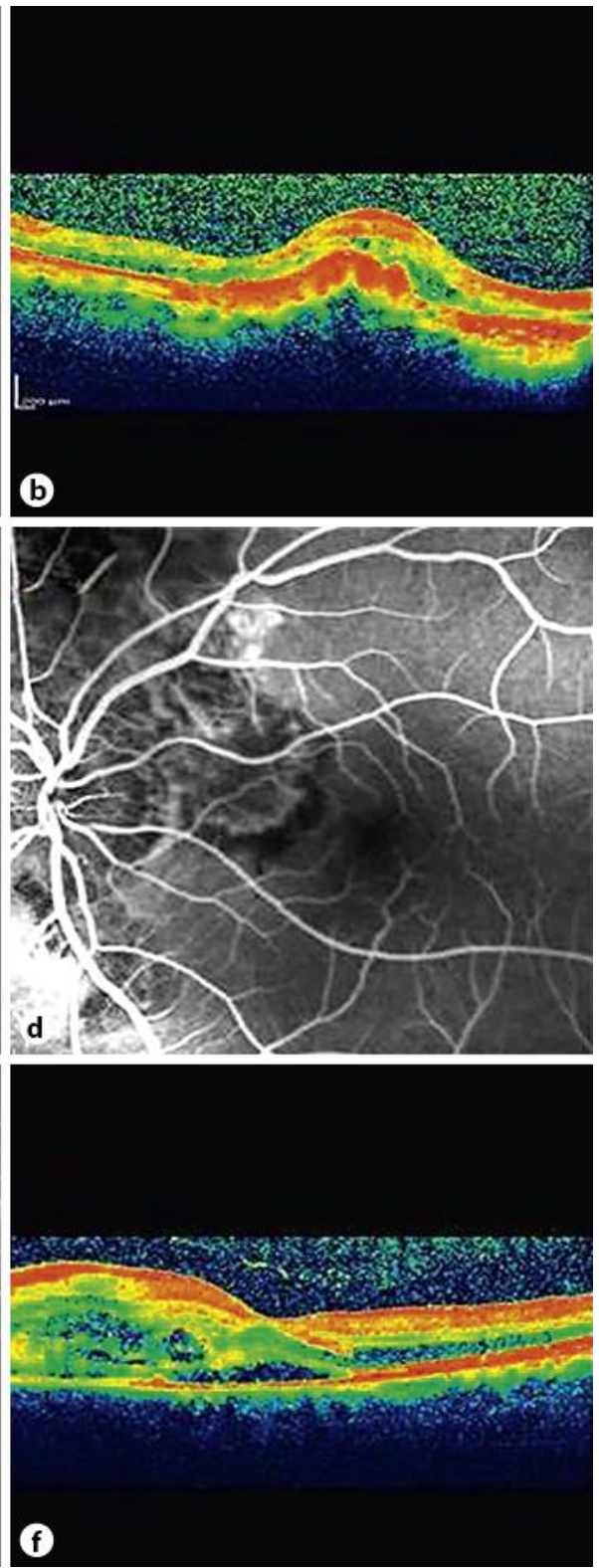

Fig. 2. Right eye. a Color fundus picture: large macular scar and extensive chorioretinal scarring around the optic disc. b OCT scan: subfoveal fibrosis. Left eye. c Color fundus picture: peripapillary chorioretinal scarring with creamy, ill-defined borders and a grayish lesion with subretinal hemorrhage in the papillomacular bundle. $\mathbf{d}$ Fluorescein angiogram: early venous phase, lacy extrafoveal hyperfluorescence with a hypofluorescent rim and relative hypofluorescence of the peripapillary area. e Fluorescein angiogram: venous phase. Composite picture showing the increased hyperfluorescence related to the active disease and coexistent CNV. f OCT scan: hyperreflective material with intraretinal and subretinal fluid in the papillomacular bundle. 
Case Reports in

Ophthalmology

\begin{tabular}{l|l}
\hline Case Rep Ophthalmol 2015;6:408-414 \\
\hline DOI: 10.1159/000442346 & $\begin{array}{l}\text { @ } 2015 \text { The Author(s). Published by S. Karger AG, Basel } \\
\text { www.karger.com/cop }\end{array}$ \\
\hline
\end{tabular}

Saatci et al.: Simultaneous Single Dexamethasone Implant and Ranibizumab Injection in a Case with Active Serpiginous Choroiditis and Choroidal Neovascular Membrane

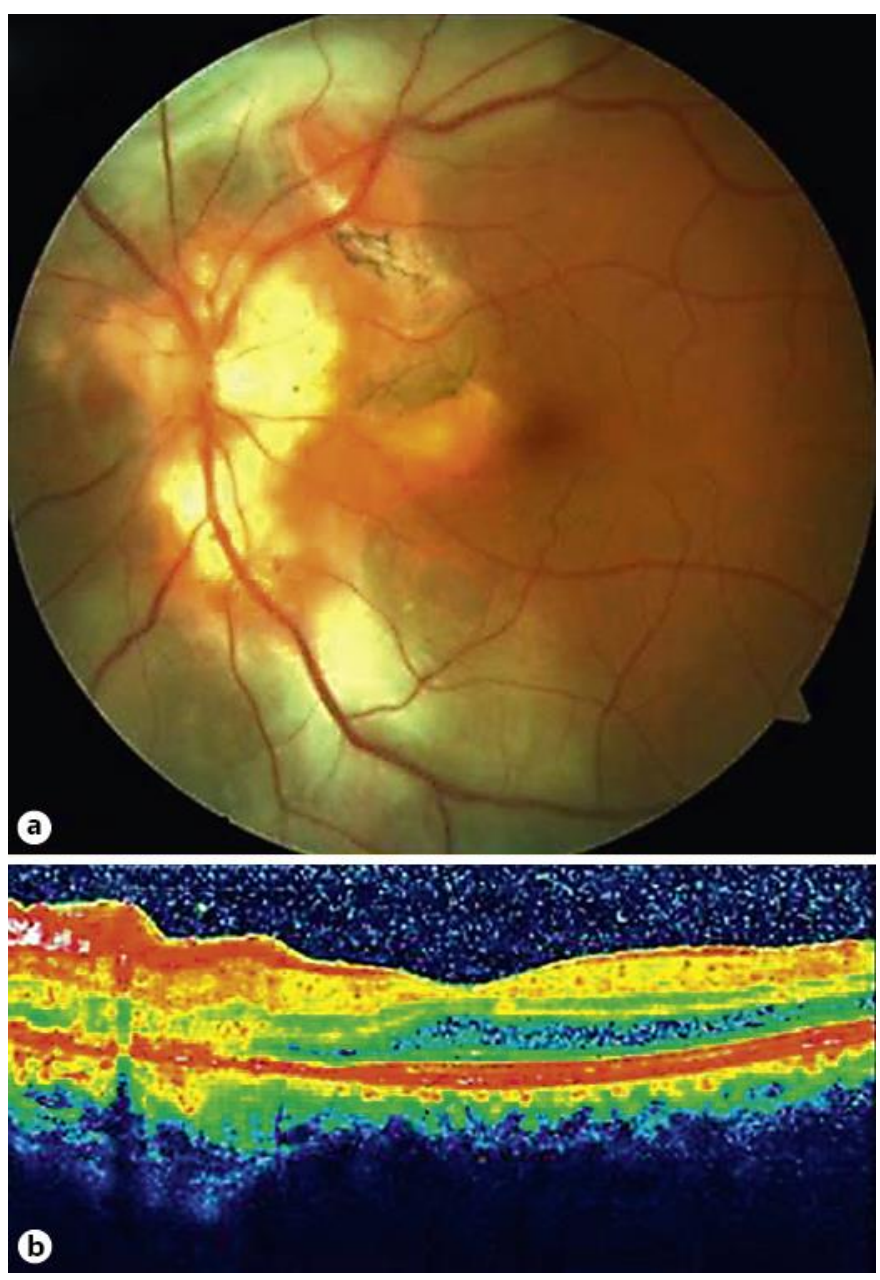

Fig. 3. Left eye. a Color fundus picture: chorioretinal scarring around the optic disc with normal-looking fovea. b OCT scan: normal foveal contour with a residual scar in the papillomacular bundle. 